\title{
World hepatitis day in Burkina Faso, 2017: seroprevalence and vaccination against hepatitis B virus to achieve the 2030 elimination goal
}

\author{
Birama Diarra ${ }^{1,2+}$, Albert Theophane Yonli ${ }^{1,2+}$, Abdoul Karim Ouattara ${ }^{1,2^{*}}$ (D), Theodora Mahoukèdè Zohoncon ${ }^{1,2}$, \\ Lassina Traore ${ }^{1,2}$, Christelle Nadembega ${ }^{2}$, Dorcas Obiri-Yeboah ${ }^{3}$, Justine Yara ${ }^{4,5}$, Virginio Pietra ${ }^{1}$, Paul Ouedraogo ${ }^{5}$, \\ Alain Bougouma ${ }^{6}$, Rokia Sanogo ${ }^{7}$ and Jacques Simpore ${ }^{1,2,5}$
}

\begin{abstract}
Background: Burkina Faso is a high endemicity country for HBV infection. However, there are few data on vaccine coverage against HBV. The aim of this study was to contribute to the improvement of HBV vaccine coverage in Ouagadougou through HBV screening.

Methods: Awareness campaigns and voluntary hepatitis B screening were organized in the twelve districts of Ouagadougou by the "SOS Hepatitis Burkina" association. A rapid HBsAg detection test (Abon Biopharma Guangzhou, Co., Ltd. Chine) was performed on 2216 individuals, who voluntarily answered a series of questions. Vaccination against hepatitis B was proposed to HBV negative participants.
\end{abstract}

Results: In a sample of 2216 participants, aged 1 to 78 years (mean age $29.7 \pm 14.7$ years); a prevalence of 10.4\% (230/2216) of HBsAg was obtained. This prevalence was high in the age groups 31 to 40 years (14.5\%) and 41 to 50 years (15.0\%). The prevalence of HBV was higher in the sixth district (14.3\%) of Ouagadougou. At the end of the screening, 1202/1986 HBV negative participants were vaccinated, resulting in a vaccination rate of $60.5 \%$. Vaccination coverage ranged from 44.5 to $73.7 \%$ all twelve districts.

Conclusions: This study still reports a high prevalence of HBV infection among young people with a peak in the sixth district of Ouagadougou. The study achieved high vaccination coverage in all age groups and districts of Ouagadougou.

Trial registration: The present study has been approved by the Ethics Committee for Health Research of Burkina Faso. CERS201501006 Registered 14 January 2015.

Keywords: Hepatitis B, Awareness, Screening, Vaccination

\section{Background}

Hepatitis B, caused by the hepatitis B virus (HBV), is a major cause of liver disease morbidity and mortality worldwide [1]. Chronic HBV infection can cause liver cirrhosis and hepatocellular carcinoma (HCC) [2]. The World Health

\footnotetext{
*Correspondence: ak.ouattara02@gmail.com

${ }^{\dagger}$ Birama Diarra and Albert Theophane Yonli contributed equally to this work. 'Biomolecular Research Center Pietro Annigoni (CERBA), BP 364,

Ouagadougou 01, Burkina Faso

${ }^{2}$ Laboratory of Molecular Biology and Molecular Genetics (LaBioGene) UFR/

SVT, University Ouaga I Prof Joseph KI-ZERBO, BP 7021, Ouagadougou 03,

Burkina Faso

Full list of author information is available at the end of the article
}

Organization (WHO) estimates an about two billion people are infected with this virus around the world and more than 360 million cases of chronic infections. About 686,000 deaths each year are attributed to the consequences of HBV infection [1]. HBV is transmitted parenterally via apparent percutaneous or per-mucous exposure to blood or other infected body fluids [3]. HBV infection is endemic in sub-Saharan Africa and causes about $44 \%$ of liver cirrhosis cases and $47 \%$ of hepatocellular carcinoma cases [4].

Burkina Faso is a country with high HBV endemicity with prevalence of more than $8 \%$ in the general population [5]. Prevalence of 9.5 to $14.5 \%$ of HBV infection has 
been reported in the general population of Ouagadougou $[6,7]$. In addition, prevalence rates of 12.1 and $9.3 \%$ were reported among the staff of Nanoro health district and pregnant women in Ouagadougou, respectively [8, 9]. It varied between 13 and $19 \%$ among blood donors in Burkina Faso $[6,10,11]$.

The risk of acquiring HBV infection in Burkina Faso remains high, not only because of its high prevalence, but also because of the low vaccination rate among the general population. Prevention seems to be the public health intervention with the greatest impact on the elimination of viral hepatitis [12]. It is within this framework that the World Health Organization (WHO) has announced its strategy prioritizing actions to eliminate viral hepatitis $B$ in most parts of the world and control it in other regions by 2030 [13]. Thus, it has set targets to be achieved by 2030, namely: a $90 \%$ reduction in new cases of chronic hepatitis $\mathrm{B}$ and $\mathrm{C}$ and a $65 \%$ reduction in mortality due to these two infections [14].

Many countries in sub-Saharan Africa are now in the process of developing viral hepatitis management guidelines and strategic plans to achieve these goals for viral hepatitis elimination [15]. In Burkina Faso, the lack of better organization of awareness campaigns, screening and vaccination against hepatitis $B$ remain one of the obstacles to HBV elimination. Thus, a study carried in Burkina Faso showed that development of awareness and screening campaigns on $\mathrm{HBV}$ can increase the vaccination coverage in the population [7]. Therefore, the objective of this study was to contribute to the improvement vaccine coverage against hepatitis $\mathrm{B}$ in the population of Ouagadougou through HBV screening and vaccination.

\section{Methods}

\section{Study population}

The present study was approved by the Ethics Committee for Health Research of Burkina Faso (DELIBERATION - $\mathrm{N}^{\circ}$ 2015-01-006) and the Institutional Ethics Committee of the Center for Biomolecular Research Pietro Annigoni/Laboratory of Molecular Biology and Genetics (CERBA/LaBioGene) [7]. The present study was conducted in Ouagadougou, Burkina Faso in July 2017 on World Hepatitis Day. The study was carried out in collaboration with the non-profit "SOS Hépatite Burkina" association during the awareness and screening campaign, which took place during July 10-30, 2017. The campaign was implemented in the twelve districts of Ouagadougou city. We used media (radio and television), advertisements, brochures, and conferences to raise awareness. Awareness focused on the routes of transmission, risk groups, symptoms, complications, and prevention against hepatitis virus infection. Participation was free and voluntary, and participants answered a questionnaire on age, sex, marital status, profession, and vaccination status for HBV.

\section{Sample collection}

The convenience sampling method was used in this study to select volunteers attending the campaign; the sampling process was preceded by individual counseling. All study participants gave their free written and informed consent according to the Helsinki Declarations during this pretest counseling and all volunteers were included in the study, regardless of age, gender, profession, or social status. People who were known to be HBsAg-positive already were excluded from the study. Venous blood samples, collected from HBsAg-positive subjects, were centrifuged, and the plasma was stored at $-20^{\circ} \mathrm{C}$ until further use.

\section{Serology of HBsAg}

The HBV rapid test kit (ABON Biopharm Hangzhou Co. Ltd., China; sensitivity > 99.0\%; specificity, 96.8\%; accuracy, 98.3\%) [16, 17] was used for the rapid diagnosis of HBsAg. The results were presented to the participants during individual posttest counseling. Vaccination with a recombinant hepatitis $B$ vaccine (EUVAX- ${ }^{\circ}$ ) was recommended to HBV-negative participants, based on the absence of $\mathrm{HBV}$ vaccination history ( $\mathrm{AbHBc}$ and $\mathrm{AbHBs}$ ). "SOS Hepatitis Burkina" association is in close collaboration with general practitioners and gastroenterologists for follow-up and adequate management of study participants tested positive for hepatitis $B$ and vaccination of HBsAg-negative individuals throughout the year. However, the latter should contribute (32 Euros for the 3 doses) for vaccination against hepatitis B because of lack of funding for vaccination in this study. On-site vaccination was provided by the association during the study period and at its headquarters throughout the year, thus making it possible to track the vaccination rates. When they received the first dose of the vaccine during the study period, participants were then follow-up by a text message reminder for the next vaccine dose, within the week of its due date until the completion of the vaccine three doses.

\section{Limit of the study}

Due to limited financial resources and lack of vaccine subsidies, we could not perform HCV screening for all the participants and were unable to vaccinate all HBsAg-negative subjects. Vaccinated cases received the first dose of $\mathrm{HBV}$ vaccine after screening. The second and third doses were administered at 1 and 5 months after the second dose, respectively. Except the first dose of the hepatitis $B$ vaccine, the second and third doses were administered by appointment at the headquarters of the "SOS Hepatitis Burkina" association.

\section{Statistical analysis}

The data collected was analyzed using SPSS 21.0 and Epi info version 7.0 software. The chi-square test was used 
for comparisons, and $p$ value $\leq 0.05$ was considered statistically significant.

\section{Results}

Sociodemographic characteristics of the study population Table 1 shows the sociodemographic characteristics of the study population. Two thousand two hundred sixteen (2216) participants, including 1221 (55.1\%) women and 995 (44.9\%) men, aged 1 and 78 years (mean age $29.7 \pm$ 14.7 years), participated in this screening campaign.

Young people constitute the majority age groups ( $\leq 20$ years is $24.6 \%$, and that 21 to 30 years is $32.4 \%$ ) (Table 1). Depending on the type of activity, the majority were students $(38.0 \%$ or $843 / 2216)$, followed by civil servants $(24.0 \%$ or $530 / 2216)$. In terms of marital status, $58.2 \%(1290 / 2216)$ were single, and $40.0 \%(886 / 2216)$ were married (Table 1). Among 2216 screened cases, 230 (10.4\%) were HBsAg-positive (Table 1).

\section{HBV infection by sociodemographic characteristics of study population $(N=2216)$}

The prevalence of HBV was higher among men (13.4\%) than women $(7.8 \%)$ with a statistically significant difference

Table 1 Sociodemographic Characteristics of the Study Population $(n=2216)$

\begin{tabular}{|c|c|c|c|}
\hline Variables & $N$ & $\%$ & Mean age \\
\hline \multicolumn{4}{|l|}{ Sex } \\
\hline Female & 1221 & 55.1 & $29.6 \pm 14.5$ \\
\hline Male & 995 & 44.9 & $29.8 \pm 15.0$ \\
\hline \multicolumn{4}{|l|}{ Age } \\
\hline$\leq 20$ & 545 & 24.6 & $11.6 \pm 5.6$ \\
\hline $21-30$ & 719 & 32.4 & $26.0 \pm 2.8$ \\
\hline $31-40$ & 516 & 23.3 & $35.0 \pm 2.8$ \\
\hline $41-50$ & 207 & 9.3 & $45.1 \pm 2.7$ \\
\hline$>50$ & 229 & 10.3 & $58.5 \pm 7.5$ \\
\hline \multicolumn{4}{|l|}{ Activity } \\
\hline Trader & 164 & 7.4 & $36.3 \pm 12.1$ \\
\hline Pupil/Student & 843 & 38.0 & $16.6 \pm 8.7$ \\
\hline Civil servant & 530 & 24.0 & $40.5 \pm 11.4$ \\
\hline Housewife & 278 & 12.5 & $41.5 \pm 11.9$ \\
\hline Informal sector & 401 & 18.1 & $36.0 \pm 11.3$ \\
\hline \multicolumn{4}{|l|}{ Marital Status } \\
\hline Single & 1290 & 58.2 & $20.8 \pm 10.8$ \\
\hline Divorced & 13 & 0.6 & $45.0 \pm 10.0$ \\
\hline Married & 886 & 40.0 & $41.0 \pm 11.5$ \\
\hline Widow & 27 & 1.2 & $51.8 \pm 8.6$ \\
\hline \multicolumn{4}{|l|}{ Serology (HBsAg) } \\
\hline Negative & 1986 & 89.6 & $29.2 \pm 15.0$ \\
\hline Positive & 230 & 10.4 & $33.8 \pm 11.6$ \\
\hline
\end{tabular}

$(p=0.001)$ (Table 2). It was high in the age groups 31 to 40 years $(12.5 \%)$ and 41 to 50 years $(15.0 \%)$ (Table 2). HBV infection was higher among informal sector workers (14.4\%), traders (12.8\%) and civil servants (12.2\%). It was lower among students (7.6\%) (Table 2). About $11.6 \%$ of married people were HBV infected compared to $11.1 \%$ of single people.

\section{Vaccination rate following HBV screening by sex and age group}

Vaccination against hepatitis $\mathrm{B}$ was recommended to HBV-negative participants. Among 1986 HBV-negative subjects in this campaign, 1202 participants received all three doses of the vaccine giving a vaccination rate of $60.5 \%$ (Table 3). Among vaccinated persons, 55.6\% (668/ $1202)$ were women and $44.4 \%(534 / 1202)$ were men.

The vaccination rate was statistically higher among women than men $(33.6 \%$ vs $26.9 \%, p<0.001)$ (Table 3$)$. The vaccinated persons were mostly young people whose mean age was $24.6 \pm 4.7$ years (Table 3 ).

\section{Distribution of $\mathrm{HBV}$ infection and vaccination rate according to the districts of Ouagadougou city}

The prevalence of HBV infection ranged from $6.6 \%$ in districts 5 and 12, to $14.3 \%$ in district 6 (Table 4). Vaccination coverage in all twelve districts and ranged

Table 2 HBV infection by sociodemographic characteristics of study population $(N=2216)$

\begin{tabular}{llll}
\hline Variables & HBV & $\%$ & $P$ value \\
& Positive/Total & & \\
\hline Sex & & & \\
Female & $96 / 1221$ & 7.8 & $<0.001$ \\
Male & $134 / 995$ & 13.4 & \\
Age & & & \\
$\quad \leq 20$ & $19 / 545$ & 3.5 & Ref \\
$21-30$ & $81 / 719$ & 11.3 & 0.0001 \\
$31-40$ & $75 / 516$ & 14.5 & 0.0001 \\
$41-50$ & $31 / 207$ & 15.0 & 0.0001 \\
> 50 & $24 / 229$ & 10.5 & 0.0001 \\
Activity & & & \\
Pupil/Student & $64 / 843$ & 7.6 & Ref \\
Trader & $21 / 164$ & 12.8 & 0.0280 \\
Civil servant & $65 / 530$ & 12.2 & 0.0038 \\
Housewife & $22 / 278$ & 7.9 & 0.8612 \\
Informal sector & $58 / 401$ & 14.4 & 0.0001 \\
Marital status & & & \\
Single & $150 / 1290$ & 11.6 & - \\
Widow and divorced & $2 / 40$ & 5.0 & 0.2958 \\
Married & $98 / 886$ & 11.1 & 0.6826 \\
\hline
\end{tabular}


Table 3 Vaccination rate following HBV screening by sex and age group

\begin{tabular}{|c|c|c|c|c|c|c|}
\hline Variables & Vaccinated $^{\mathrm{a}} /$ Total & $\%$ & 1st dose & 2nd dose & 3rd dose & Mean age \\
\hline \multicolumn{7}{|l|}{ Sex } \\
\hline Female & $668 / 1139$ & 58.6 & 675 & 672 & 668 & $29.8 \pm 13.8$ \\
\hline Male & $534 / 847$ & 63.0 & 545 & 535 & 534 & $30.1 \pm 14.1$ \\
\hline Total & 1202/1986 & 60.5 & 1220 & 1207 & 1202 & $24.6 \pm 4.7$ \\
\hline \multicolumn{7}{|l|}{ Age } \\
\hline$\leq 20$ & $210 / 474$ & 44.3 & 215 & 211 & 210 & $12.8 \pm 5.4$ \\
\hline $21-30$ & $436 / 664$ & 65.7 & 441 & 437 & 436 & $26.1 \pm 2.8$ \\
\hline $31-40$ & $316 / 459$ & 68.8 & 318 & 317 & 316 & $35.0 \pm 2.8$ \\
\hline $41-50$ & 119/192 & 62.0 & 122 & 120 & 119 & $45.0 \pm 2.8$ \\
\hline$>50$ & $121 / 197$ & 61.4 & 124 & 122 & 121 & $57.5 \pm 6.0$ \\
\hline \multicolumn{7}{|c|}{ Number of vaccinated individuals } \\
\hline Female & $668 / 1202$ & 55.6 & 675 & 672 & 668 & $29.5 \pm 12.7$ \\
\hline Male & $534 / 1202$ & 44.4 & 545 & 535 & 534 & $30.1 \pm 11.2$ \\
\hline \multicolumn{7}{|c|}{ Vaccination rate } \\
\hline Female & $668 / 1986$ & 33.6 & 675 & 672 & 668 & $29.8 \pm 13.8$ \\
\hline Male & 534/1986 & 26.9 & 545 & 535 & 534 & $29.9 \pm 13.9$ \\
\hline
\end{tabular}

${ }^{a} \mathrm{All}$ vaccinated $\mathrm{HBsAg}$ individuals completed their three doses of hepatitis $\mathrm{B}$ vaccine

between 44.5 to $73.7 \%$ (Table 4). The prevalence of HBV infection was significantly higher in district six compared to district four $(p=0.024)$, five $(p=0.002)$ and twelve $(p=0.047)$. District 1 also had a significantly higher prevalence compared to district $5(p=0.035)$.

\section{Discussion}

Since 2010, WHO has instituted the World Hepatitis Day in order to enable people to better know this infection and ways to protect themselves. Thus, every year, on the occasion of this day, the "SOS Hepatitis"

Table 4 Distribution of HBV infection and vaccination rate according to the districts of Ouagadougou city

\begin{tabular}{|c|c|c|c|c|c|c|}
\hline \multirow[t]{2}{*}{ Districts } & \multicolumn{3}{|l|}{$\mathrm{HBV}$} & \multicolumn{3}{|c|}{ Vaccination } \\
\hline & $\mathrm{N}$ & Positive & $\%$ & $\mathrm{~N}$ & Vaccinated & $\%$ \\
\hline $1^{*}$ & 214 & 26 & 12.1 & 188 & 136 & 72.3 \\
\hline 2 & 111 & 12 & 10.8 & 99 & 73 & 73.7 \\
\hline 3 & 245 & 23 & 9.4 & 222 & 140 & 63.1 \\
\hline $4^{*}$ & 260 & 22 & 8.5 & 238 & 168 & 70.6 \\
\hline $5^{*}$ & 259 & 17 & 6.6 & 242 & 173 & 71.5 \\
\hline $6^{*}$ & 413 & 59 & 14.3 & 354 & 214 & 60.4 \\
\hline 7 & 218 & 23 & 10.5 & 195 & 90 & 46.2 \\
\hline 8 and 9 & 52 & 4 & 7.7 & 48 & 26 & 54.2 \\
\hline 10 & 173 & 18 & 10.4 & 155 & 69 & 44.5 \\
\hline 11 & 180 & 20 & 11.1 & 160 & 74 & 46.3 \\
\hline $12^{*}$ & 91 & 6 & 6.6 & 85 & 39 & 45.9 \\
\hline
\end{tabular}

association conducts voluntary screening activities against hepatitis B in Ouagadougou city. This year, the overall seroprevalence of hepatitis B virus was $10.4 \%$, including $6.1 \%$ for men and $4.3 \%$ for women. This prevalence of $10.4 \%$ is lower than $14.5 \%$ reported in the general population of Ouagadougou [18]; and those 12.9 to $17.3 \%$ reported among blood donors in Burkina Faso $[19,20]$. However, our prevalence is similar to the $9.8 \%$ reported in the general population of Ouagadougou [7]; and 9.3 to $9.8 \%$ reported among pregnant women in Burkina Faso [5, 8].

The variations in prevalence rates could be explained by the size and type of the study population, by the limitations of serological tests use, immunity and other socioeconomic characteristics. It should be also mentioned that voluntary participation in a screening program introduces self-selection bias. The variation in the prevalence of HBV infection in the twelve districts of Ouagadougou ( 4.2 to $14.3 \%$ ) could be explained by the difference in population participation rates to voluntary screening campaigns. HBV infection has a distribution of leopard spots with areas of high prevalence (district 1 and 6) corresponding to black spots separated by areas of low prevalence (district 4, 5 and 12). These results demonstrate that the frequency of HBV infection varies not only across countries, but also between different geographical areas within a city and suggest that HBV infection prevalence data are needed at sub-national level to estimate disease burden and guide health and vaccine policy. These differences in HBV infection prevalence between cities could be due to a lack of 
infrastructure within certain cities to provide hepatitis B vaccine especially since the best-developed areas had the lowest prevalence in this study.

The high prevalence of 11.3 and $14.5 \%$ found in the 21 to 30 and 31 to 40 age groups in this study, respectively, show that young people are the most affected by HBV infection. These young people constituted also the most important group of volunteer screening. These results corroborate those of 15.9 and $16.3 \%$ of Tao et al. [18] and 11.6 and $13.1 \%$ of Diarra et al. [7] reported among young people in Ouagadougou, Burkina Faso. They are also similar to those of $22.2 \%$ of Makuwa et al. [21] reported among young people in Gabon. This high prevalence of HBV among young people could be explained by use of nonsterile syringes among intravenous drug users, customary scarification rites, male and female circumcision with soiled blades. The reduction in prevalence from 15.0 to $10.5 \%$ observed in the age groups 41 to 50 and $>50$ years, respectively, could be due to the increase in the number of deaths following liver cirrhosis or hepatocellular carcinoma in patients $>50$ years.

Despite the consequences that may be caused by HBV infection, there is no national strategy or plan for awareness and to fight against viral hepatitis B in Burkina Faso, because viral hepatitis $B$ is not considered a priority disease. However, the present study achieved a $60.5 \%$ $(1202 / 1986)$ vaccine coverage against hepatitis B after screening. This vaccination rate evolved around $50.0 \%$ in all age groups and between 44.5 and $73.7 \%$ in all districts of Ouagadougou city. The high participation rate $(95.0 \%$ or $1887 / 1986)$ to vaccination is an affirmation of the Burkinabe people's concern about viral hepatitis B.

However, in absence of a subsidy, the cost of the vaccine remains high and constitutes a barrier despite the willingness of participants to be vaccinated against hepatitis $\mathrm{B}$. A recent study reports that to achieve the WHO goals of eliminating HBV by 2030, sub-Saharan Africa will need to actively prioritize implementation of several elimination strategies.

"In addition, antenatal HBsAg screening, prevention of mother-to-child transmission with administration of tenofovir to pregnant women who are HBV monoinfected with HBV DNA concentrations higher than 20,000 IU/mL, together with HBV birth-dose vaccination, and ensuring subsequent full HBV-vaccine coverage should form the cornerstone of any HBV elimination strategy [15]". ${ }^{1}$ Chotun et al. [22] also reported the importance of HBV screening among pregnant women and the need to vaccinate newborns within $24 \mathrm{~h}$ of birth. We hope that the report will also stimulate dialogue with respect to the roles of all stakeholders in forging a cohesive and effective response to viral hepatitis in Burkina Faso. Thus, we suggest that the government considers viral hepatitis B a priority disease, commemorate World Hepatitis Day and promote other awareness raising activities.

\section{Conclusion}

The voluntary screening campaign of the non-profit "SOS Hépatite Burkina" association in 2017 reported a prevalence of $10.4 \%$ of HBsAg in the population of Ouagadougou. Prevalence was relatively high among young people and in the majority of districts of Ouagadougou city. This campaign achieved a vaccination coverage of $60.5 \%$ after screening. This coverage was high in all age groups and in all districts of Ouagadougou city. The study suggests an active involvement of the Burkinabe government in the fight against viral hepatitis B through its recognition as a priority disease, commemorate World Hepatitis Day and promote other awareness raising activities and the reduction of cost of the vaccine.

\section{Endnotes}

${ }^{1}$ Spearman et al. [15] Page 907.

\section{Abbreviations}

CERBA: Pietro Annigoni Biomolecular Research Center; HBsAg: Hepatitis B Surface Antigen; HBV: Hepatitis B Virus; HCC: Hepatocellular Carcinoma; LaBioGene: Laboratory of Molecular Biology and Genetics; WHO: World Health Organization

\section{Acknowledgements}

The authors wish to thank the "SOS Hepatitis Burkina" association and all its partners, who annually conduct outreach and screening against hepatitis B. A deep gratitude to the Saint Camille Hospital of Ouagadougou (HOSCO), the Biomolecular Research Center Pietro Annigoni of Ouagadougou (CERBA) and the Italian Episcopal Conference (CEI).

\section{Funding}

The non-profit "SOS hepatitis Burkina" association and CERBA/LaBioGene provided material and technical support.

\section{Availability of data and materials}

The datasets used and/or analyzed during the current study are available from the corresponding author on reasonable request.

\section{Authors' contributions}

JS, BD and ATY conceived and designed the study. BD, ATY, AKO, JY, LT and TMZ were involved in data generation, collection and assembly. BD, ATY and AKO were involved in data analysis and interpretation. BD, ATY, AKO, TMZ, $L T, C N, D O-Y, J Y, V P, P O, A B, R S$ and JS were involved with drafting or revising the manuscript. JS, BD, ATY and JY provided administrative, technical and material support. Supervision of the study was made by JS. All authors critically revised and approved the final version of this publication.

\section{Ethics approval and consent to participate}

Approval for the study was obtained from the National Health Ethic Committee ( $N^{\circ}$ 2015-01-006). All study participants gave their free written and informed consent.

\section{Consent for publication \\ Not Applicable.}

Competing interests

The authors declare that they have no competing interests. 


\section{Publisher's Note}

Springer Nature remains neutral with regard to jurisdictional claims in published maps and institutional affiliations.

\section{Author details}

'Biomolecular Research Center Pietro Annigoni (CERBA), BP 364, Ouagadougou 01, Burkina Faso. ${ }^{2}$ Laboratory of Molecular Biology and Molecular Genetics (LaBioGene) UFR/SVT, University Ouaga I Prof Joseph KI-ZERBO, BP 7021, Ouagadougou 03, Burkina Faso. ${ }^{3}$ Department of Microbiology and Immunology, School of Medical Sciences, University of Cape Coast, Cape Coast, Ghana. ${ }^{4}$ SOS Hepatitis, Ouagadougou, Burkina Faso. ${ }^{5}$ Saint Camille Hospital of Ouagadougou (HOSCO), BP 444, Ouagadougou 01, Burkina Faso. ${ }^{6}$ Gastroenterology Service, CHU Yalgado OUEDRAOGO, Ouagadougou, Burkina Faso. ${ }^{7}$ Faculty of Pharmacy, University of Technical Sciences and Technologies of Bamako (USTTB), Bamako, Mali.

Received: 23 March 2018 Accepted: 26 July 2018

Published online: 06 August 2018

\section{References}

1. WHO. Global hepatitis report 2017. World Health Organization Geneva; 2017. http://www.who.int/hepatitis/publications/global-hepatitis-report2017/ en/. Accessed 02 Aug 2018

2. Zhou JY, Zhang L, Li L, Gu GY, Zhou YH, Chen JH. High hepatitis B virus load is associated with hepatocellular carcinomas development in Chinese chronic hepatitis B patients: a case control study. Virol J. 2012;9:16.

3. Chien YC, Jan CF, Kuo HS, Chen CJ. Nationwide hepatitis B vaccination program in Taiwan: effectiveness in the 20 years after it was launched. Epidemiol Rev. 2006;28:126-35.

4. Perz JF, Armstrong GL, Farrington LA, Hutin YJ, Bell BP. The contributions of hepatitis $B$ virus and hepatitis $C$ virus infections to cirrhosis and primary liver cancer worldwide. J Hepatol. 2006;45:529-38.

5. Simpore J, Savadogo A, Ilboudo D, Nadambega MC, Esposito M, Yara J, et al. Toxoplasma gondii, HCV, and HBV seroprevalence and co-infection among HIV-positive and -negative pregnant women in Burkina Faso. J Med Virol. 2006;78:730-3.

6. Tao I, Compaoré TR, Diarra B, Djigma F, Zohoncon TM, Assih M, et al. Seroepidemiology of hepatitis $B$ and $C$ viruses in the general population of Burkina Faso. Hepatitis research and treatment. 2014:2014:781843.

7. Diarra B, Ouattara AK, Wendkuuni Djigma F, Rebeca Compaore T, ObiriYeboah D, Traore L, Theophile Soubeiga S, Bado P, Yara J, Pietra V, et al. World Hepatitis Day in Burkina Faso, 2016: Awareness, Screening, Identification of HBV Markers, HBV/HCV Coinfection, and Vaccination. Hepat Mon. 2017:17:e13789.

8. Simpore J, Granato M, Santarelli R, Nsme RA, Coluzzi M, Pietra V, et al. Prevalence of infection by HHV-8, HIV, HCV and HBV among pregnant women in Burkina Faso. J Clin Virol. 2004;31:78-80.

9. Pietra V, Kiema D, Sorgho D, Kabore S-PCG, Mande S, Castelli F, et al. Prévalence des marqueurs du virus de l'hépatite $B$ et des anticorps contre le virus de l'hépatite $C$ parmi le personnel du District Sanitaire de Nanoro, Burkina Faso. Science et technique, Sciences de la santé. 2008;31:53-9.

10. Nagalo MB, Sanou M, Bisseye C, Kabore MI, Nebie YK, Kienou K, et al. Seroprevalence of human immunodeficiency virus, hepatitis $B$ and $C$ viruses and syphilis among blood donors in Koudougou (Burkina Faso) in 2009. Blood Transfus. 2011;9:419-24.

11. Nagalo BM, Bisseye C, Sanou M, Kienou K, Nebie YK, Kiba A, et al. Seroprevalence and incidence of transfusion-transmitted infectious diseases among blood donors from regional blood transfusion centres in Burkina Faso. West Africa Trop Med Int Health. 2012;17:247-53.

12. Brahm J, Castera L, Hou J, Lindor K. Joint society statement for the elimination of viral hepatitis. Hepatol. 2016;64:1031-2.

13. Towards elimination of viral hepatitis by 2030. Lancet. 2016;388:308.

14. WHO. Global health sector strategy on viral hepatitis 2016-2021: towards ending viral hepatitis. Geneva: World Health Organization; 2016. www. appswhoint/iris/bitstream/10665/246177/1/WHO-HIV-201606-engpdf. Accessed 5 Dec 2017.

15. Spearman CW, Afihene M, Ally R, Apica B, Awuku Y, Cunha L, et al. Hepatitis $B$ in sub-Saharan Africa: strategies to achieve the 2030 elimination targets. Lancet Gastroenterol Hepatol. 2017;2:900-9.
16. Chizzali-Bonfadin C, Adlassnig KP, KreihsI M, Hatvan A, Horak W. Knowledgebased interpretation of serologic tests for hepatitis on the world wide web. Clin Perform Qual Health Care. 1997;5:61-3.

17. Ter Borg F, Ten Kate FJW, Cuypers HTM, Leentvaar-Kuijpers A, Oosting J, Wertheim-van Dillen PME, et al. Relation between laboratory test results and histological hepatitis activity in individuals positive for hepatitis B surface antigen and antibodies to hepatitis B e antigen. Lancet. 1998;351:1914-8.

18. Tao I, Compaore TR, Diarra B, Djigma F, Zohoncon TM, Assih M, et al. Seroepidemiology of hepatitis $B$ and $C$ viruses in the general population of Burkina Faso. Hepat Res Treat. 2014;2014:781843.

19. Collenberg E, Ouedraogo T, Ganame J, Fickenscher H, Kynast-Wolf G, Becher $H$, et al. Seroprevalence of six different viruses among pregnant women and blood donors in rural and urban Burkina Faso: a comparative analysis. J Med Virol. 2006;78:683-92.

20. Tao I, Bisseye C, Nagalo BM, Sanou M, Kiba A, Surat G, et al. Screening of hepatitis $G$ and Epstein-Barr viruses among voluntary non remunerated blood donors (VNRBD) in Burkina Faso. West Africa Mediterr J Hematol Infect Dis. 2013;5:e2013053.

21. Makuwa M, Mintsa-Ndong A, Souquiere S, Nkoghe D, Leroy EM, Kazanji M. Prevalence and molecular diversity of hepatitis $B$ virus and hepatitis delta virus in urban and rural populations in northern Gabon in Central Africa. J Clin Microbiol. 2009:47:2265-8.

22. Chotun N, Preiser W, van Rensburg CJ, Fernandez P, Theron GB, Glebe D, et al. Point-of-care screening for hepatitis $B$ virus infection in pregnant women at an antenatal clinic: a south African experience. PLoS One. 2017;12: e0181267.

\section{Ready to submit your research? Choose BMC and benefit from:}

- fast, convenient online submission

- thorough peer review by experienced researchers in your field

- rapid publication on acceptance

- support for research data, including large and complex data types

- gold Open Access which fosters wider collaboration and increased citations

- maximum visibility for your research: over $100 \mathrm{M}$ website views per year

At BMC, research is always in progress.

Learn more biomedcentral.com/submissions 